\title{
The chemotactic properties of various topical brimonidine tartrate ophthalmic preparations
}

\author{
Ruiz Simonato Alonso ${ }^{1 *} \mathbb{D}$, Helena Parente Solari ${ }^{1,2}$, Eduardo de França Damasceno', \\ Miguel Noel Nascentes Burnier Jr. ${ }^{2}$ and Marcelo Palis Ventura ${ }^{1,2}$
}

\begin{abstract}
Background: The study aimed to evaluate and compare the leukocyte chemotactic activities of various brimonidine tartrate (BT) eye drop formulations.

Methods: A 96-well dot-blot platet using a Boyden-style well was used to study the chemotactic effects of BT ophthalmic preparations. A modification was made to create blind wells where the tested agents were placed. Leukocytes were isolated from the peripheral blood of healthy volunteers. As positive controls, we used diluted drugs, benzalkonium chloride solution (BAK), zymosan-activated serum, and formyl-methionine-leucinephenylalanine peptides. The negative control in our study was a phosphate-buffered saline solution. For each experimental condition, we measured leukocyte migration through a Millipore membrane. The differences in the mean migration distance between groups were compared using the analysis of variance (ANOVA).

Results: The measured migration distances (in $\mu \mathrm{m} \pm \mathrm{SD}$ ) were $62.14 \pm 3.71$ for BT $0.2 \%$ with BAK (Alcon Laboratories Inc.); $63.61 \pm 3.81$ for BT 0.2\% with BAK (Allergan Inc); $40.36 \pm 3.17$ for BT $0.15 \%$ without BAK; and $41.02 \pm 2.17$ for BAK alone. The negative controls showed no chemotactic activity, while the positive controls showed the highest neutrophil migration of all experimental conditions. The differences between BT $0.15 \%$ without BAK and the other commercial formulations were statistically significant.

Conclusion: Commercial ophthalmic preparations of BT $0.2 \%$ with BAK $0.005 \%$ had higher chemotactic properties than the alternative of a lower concentration of BT and without the preservative BAK. Therefore, the latter should be considered for patients with glaucoma or ocular hypertension in order to minimize iatrogenic ocular inflammation.
\end{abstract}

Keywords: Brimonidine tartrate, Adverse effect, Benzalkonium chloride, Ophthalmic solutions, Glaucoma

\section{Background}

The inflammatory process is characterized by leukocyte invasion triggered by specific chemotactic factors. Leukocytes are an important cell type that both potentiate and sustain inflammation by releasing enzymes and producing various

\footnotetext{
* Correspondence: ruizsa@hotmail.com

${ }^{1}$ Department of Ophthalmology, Fluminense Federal University, Niteroi, Rio de Janeiro, Brazil

Full list of author information is available at the end of the article
}

metabolites and inflammatory mediators. These include prostaglandins, leukotrienes, and platelet-activating factors. Leukocyte locomotion and chemotactic dynamics have been the subject of numerous studies over the past few decades. Chemotactic leukocyte migration has been described as the speed or rate of motion of cells through a matrix that is induced by substances in the environment (chemokinesis), or alterations in the vectorial movement of cells towards a stimulatory agent or chemoattractant (chemotaxis) [1-4]. 
Glaucoma and ocular hypertension are related eye conditions that result from a sustained increase in eye pressure that often leads to irreversible damage of the optic nerve fibers. The natural course of the disease, if left untreated, is permanent vision loss in the affected eye. Several treatments are recommended for glaucoma and ocular hypertension, including the formulation of brimonidine tartrate (BT) $0.2 \%(2.0 \mathrm{mg} / \mathrm{mL})$ eye drops; which also includes the non-active ingredients benzalkonium chloride (BAK) $0.005 \%(0.05 \mathrm{mg} / \mathrm{mL})$, citric acid, polyvinyl alcohol, sodium chloride, sodium citrate, and purified water. Hydrochloric acid and/or sodium hydroxide are also added to achieve a physiological $\mathrm{pH}$ of 6.4. BAK is the most commonly used antimicrobial preservative in topical ophthalmic solutions. The BT $0.2 \%$ formulation is an alpha- 2 selective adrenergic agonist that has been widely used for the treatment of glaucoma and ocular hypertension since 1996 [1, 2]. Currently, there are several generic brands of BT, including some BAKfree formulations. BT lowers intraocular pressure (IOP) by reducing aqueous humor production and enhancing uveoscleral drainage $[2,3]$. When used twice daily, its efficacy is comparable to timolol $0.5 \%$, another commonly used medication to decrease IOP. However, BT has less severe chronotropic effects and is therefore considered an optimal treatment option, either as a monotherapy, adjunctive therapy, or as a substitute [4-6]. Nevertheless, BT has adverse effects that are more common than other drugs, such as dry mouth, eyelid edema, and a burning sensation in the treated eye $[7,8]$. Other toxic side effects, such as chronic dermatitis and granulomatous conjunctivitis, have also been described; and often require the medication to be discontinued. Nevertheless, when compared to beta blockers, BT has still fewer systemic side effects $[4,9-11]$.

In the attempt of reduce side-effects, another eye drop formulation introduce to the market with a lower concentration

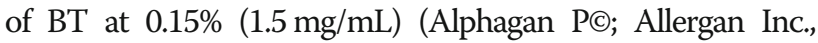
Irvine, CA, USA) and contained stabilized oxychloride complex (SOC) $0.005 \%(0.05 \mathrm{mg} / \mathrm{mL})$, instead of BAK as a preservative. This formulation also includes the inactive ingredients sodium carboxymethylcellulose, sodium borate, boric acid, sodium chloride, potassium chloride, calcium chloride, magnesium chloride, purified water, and hydrochloric acid and/or sodium hydroxide to adjust the $\mathrm{pH}$ to $7.4[12,13]$. BAK at high concentrations can be toxic and can persist for long periods in ocular tissue, eventually leading to dose-dependent cell death [14-17]. BT $0.15 \%$ also has a $25 \%$ reduction of the active drug in the formula, and animal studies suggest that brimonidine has a higher bioavailability when mixed with SOC [18]. Several studies have demonstrated that BT 0.15\% with SOC has the same efficacy as BT $0.2 \%$ with BAK for reducing IOP [19-21]. Moreover, a single study reported that the drug is more effective in dark brown irides [22].
Long-term use of topical glaucoma medications associated with preservatives can induce changes in the ocular surface and conjunctival cell infiltration [23-25]. Additionally, a common secondary complication of hypotensive eye drops is iatrogenic inflammation. Prior studies have shown that various topical glaucoma medications, such as prostaglandin analogues, beta blockers, cholinergic agonists, and carbonic anhydrase inhibitors used for the treatment of glaucoma, have leukocyte chemotactic effects [26]. Our experiment reproduces this technique to specifically investigate the inflammatory characteristics of BT. Leukocytes are central to the initiation and maintenance of inflammation through the release of enzymes and the production of inflammatory mediators. Therefore, IOP treatment with chemoattractant compounds may indirectly lead to inflammation via increased leukocyte migration [27].

Beta blockers, cholinergic agonists, and carbonic anhydrase inhibitors were once the mainstay of glaucoma therapy. However, over the last two decades, the pharmacological management of glaucoma and ocular hypertension has changed with the introduction of prostaglandin analogs. The International Council of Ophthalmology Guidelines for Glaucoma Eye Care now includes Latanoprost $50 \mu \mathrm{g} / \mathrm{mL}$ alongside timolol $0.25 \%$ or $0.5 \%$ as the two essential topical intraocular pressure-lowering medications [28]. Nevertheless, because monotherapy increases compliance, prostaglandins are currently recommended to initiate treatment as they achieve the highest reduction in IOP per a meta-analysis of randomized clinical trials [29]. Moreover, prostaglandin analogs are administered once per day, have accepted safety profiles and are currently recommended by the American Academy of Ophthalmology Preferred Practice Patterns [30]. In this new context, BT is used more broadly as a single therapy or in combination with drugs when compared to beta blockers and carbonic anhydrase inhibitors.

There are also several BT formulations that contain a variety of concentrations and preservatives that may have different chemotactic properties. To date, there has been little investigation into these newer glaucoma and ocular hypertension therapies, particularly with respect to their chemotactic properties that may lead to inflammation. Our study therefore examined the chemotactic properties of various BT formulations with regards to leukocyte migration to determine if any are better suited for avoiding undesirable inflammatory complications. This will lead to improved recommendations for the treatment of ocular hypertension and better outcomes for patients.

\section{Methods}

\section{Leukocyte isolation}

Per the rules of the national ethics research commission, in approved number project 1.466 .576 , blood was collected from 14 healthy donors, aged 21 to 55 years, in 
heparinized vacutainer tubes. An equal amount of 20 $\mathrm{mg} / \mathrm{mL}$ Ficoll 400 (Pharmacia, Upsala, Sweden) was mixed with the collected blood, a deteriorated composite solution with a density of $1.077 \mathrm{~g} / \mathrm{mL}$. During the period of 30 to $45 \mathrm{~min}$, the blood collected was exposed to room temperature to allow the red blood cells to sediment. The upper layer containing leukocytes was isolated and centrifuged at $400 \mathrm{~g}$ at room temperature for $10 \mathrm{~min}$. The supernatant was removed and discarded, and then the leukocytes were washed twice with RPMI1640 medium (Gibco BRL, Burlington, Canada) containing 5\% foetal calf serum (FCS; ICN Pharmaceuticals Canada Ltd., Montreal, Canada). Finally, the concentration of leukocytes was adjusted to $2.5 \times 10^{6}$ cells $/ \mathrm{ml}$ in RPMI. Within $30 \mathrm{~min}$ after purification, the leukocytes obtained from collection were used to evaluate the characteristics of the migration of chemotactic properties.

\section{Drug formulations and controls}

A 1:100 dilution was used to prepare the drugs for the experiment. We used zymosan-activated serum (ZAS) and the peptide formyl-methionine-leucine-phenylalanine (f-Met-Leu-Phe or fMLP) as positive controls. The negative control used was phosphate-buffered saline solution (PBS). Zymosan-activated serum was prepared by adding zymosan (Sigma-Aldrich, St. Louis, MO, USA) to fresh defibrinated human serum at a concentration of $1.35 \mathrm{mg} / \mathrm{ml}$ serum. In each of the tests, fresh frozen aliquots were used. f-Met-Leu-Phe (Sigma-Aldrich Chemical, St. Louis, MO) was used in concentrations ranging from 6 to $10 \mathrm{mg} / \mathrm{ml}$ to $100 \mathrm{mg} / \mathrm{ml}$.

\section{Migration assays}

To test the migration of leukocytes and chemotactic properties, a modified 96-well dot-blot plate (Bio-Rad Laboratories Inc., Hercules, CA, USA) was used as a Boyden-style blind well chemotaxis chamber. A modification was made to create blind wells where the tested agents were placed. A polyethylene barrier was sealed with firmly pressed solid silicone. Twenty-five microliters of each agent to be assayed was placed in each of the lower wells. We finely fit two $9 \mathrm{~cm}$ Millipore membranes (3 $\mu$ mpore size) (Millipore Corporation, Bedford, MA, USA) to the rectangular collector and placed them in the lower collector containing the chemoattractive solution. A thorough visual inspection was carried out to ensure consistent suitability, without the possibility of wrinkles on the membrane surface, ensuring homogeneous conditions in the wells. Leukocyte suspensions $(100 \mu \mathrm{L})$ containing an estimated 250.000 cells were placed in each of the upper wells. Finally, the entire assay of the chemotactic apparatus was incubated in a humidified atmosphere containing $5 \% \mathrm{CO}_{2}$ for $90 \mathrm{~min}$ at a controlled temperature at $37^{\circ} \mathrm{C}$.

\section{Membrane staining technique}

After incubation, a $0.85 \% \mathrm{NaCl}$ solution was used to gently rinse the membrane, which was subsequently fixed for a period of $15 \mathrm{~s}$ in $100 \%$ ethanol and then rinsed with distilled water. Mayer's haematoxylin was used as a rinsing solution for another $6 \mathrm{~min}$, and the membrane was washed with water and bleached with acid alcohol for another $1 \mathrm{~min}$. After washing with water one more time, the membrane was exposed to mild alkali for $2 \mathrm{~min}$. The membranes were let to dry overnight at a controlled temperature of $37^{\circ} \mathrm{C}$. The next day, the membrane was made transparent after being subjected to an immersion bath in $100 \%$ xylene solution to finally be mounted on a glass slide for reading under a calibrated microscope.

\section{Measuring leukocyte migration}

Leukocyte migration was evaluated using a Millipore membrane (Millipore). Migration was measured using a microscope where the Vernier graduated in micrometres $(\mu \mathrm{m})$ was calibrated to obtain proper measurements at $100 \times$ magnification. Initially, we observed the cells on the upper surface, and the first mark was recorded. Then, we moved the focus into the membrane until the most distant leukocytes were identified, and this new position at the Vernier was recorded. The migration distance was established as the difference between the two registered positions. Five independent readings were taken for each sample considering different cells in the initial position. Each dilution was checked twice, and the average migration distance was used in our statistical analysis (Fig. 1).

\section{Statistical analysis}

ANOVA (analysis of variance) was used to determine if the observed differences in mean migration distance were significant. A post hoc least significant difference (LSD) test was used for multiple comparisons. Values of $p<0.01$ were considered statistically significant. The SPSS statistical software version 21.00 (IBM Corp., Armonk, NY, USA) was used for all statistical analyses.

\section{Results}

The measured migration distances $(\mu \mathrm{m} \pm \mathrm{SD})$ were $62.14 \pm 3.71$ for BT $0.2 \%$ with BAK (Alcon Laboratories Inc); $63.61 \pm 3.81$ for BT $0.2 \%$ with BAK (Allergan Inc); $40.36 \pm 3.17$ for BT $0.15 \%$ without BAK and $41.02 \pm 2.17$ for BAK alone. The negative controls showed no chemotactic activity, while the positive controls showed the highest neutrophil migration of all experimental conditions. The differences between BT $0.15 \%$ without BAK and the other commercial formulations were statistically significant $(p<0.01)$ (Tables 1 and 2$)$. 


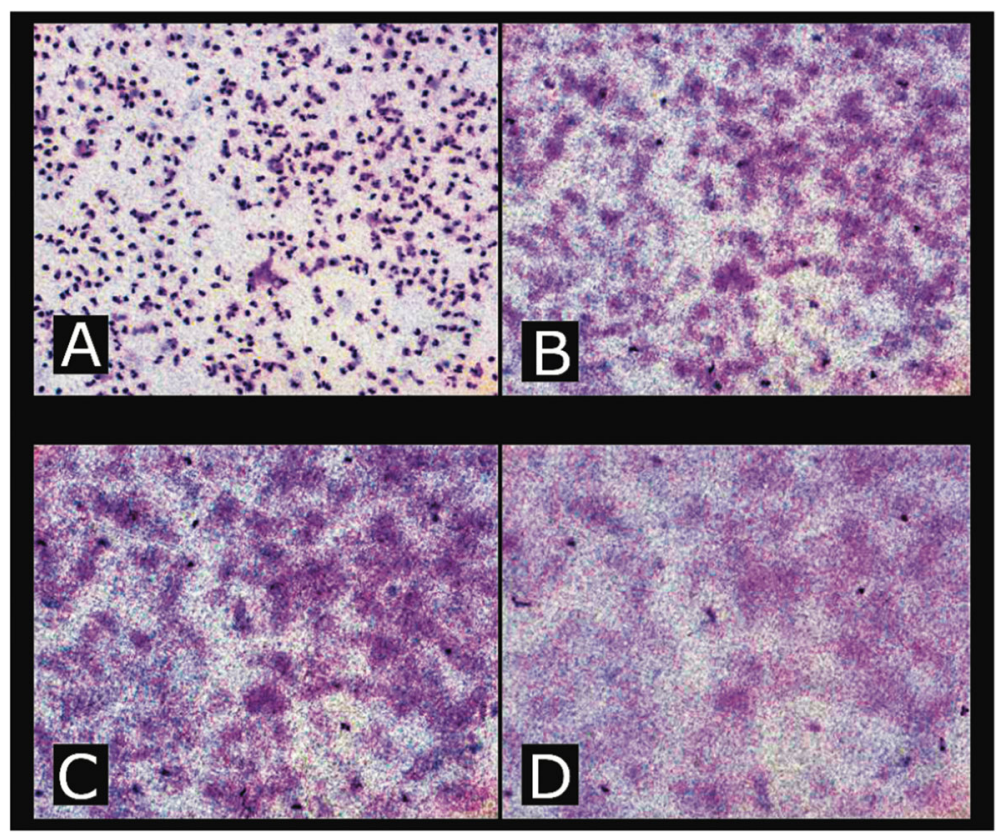

Fig. 1 Leukocyte migration was evaluated using a Millipore membrane (Millipore). Migration was measured using a microscope where the Vernier graduated in micrometres $(\mu \mathrm{m})$ was calibrated to obtain the measurements. The microscope was focused onto the cells on the upper surface of the membrane (a) and the position of the fine focus Vernier recorded. The depth of focus was then advanced through the membrane ( $\mathbf{b}$ and $\mathbf{c}$ ) until the last and furthest migrating cells were seen. At that position, the mark on the calibrated Vernier was again recorded (d). All photographs taken at 100x magnification

BT $0.15 \%$ without BAK and BAK $0.005 \%$ solution had no significant chemotactic effects, and the difference between these two experimental conditions was not significantly different $(p=0.25)$. Both the positive controls, ZAS and fMLP, showed a significant chemotactic effect and had the longest migration distances. The PBS negative control showed a negligible migration distance (Fig. 2).

Table 1 Effects of different brimonidine eye drops formulations on neutrophil migration

\begin{tabular}{|c|c|}
\hline Drugs (1:100 dilution) & Migration distance \pm SD $(\mu \mathrm{m})$ \\
\hline BT $0.2 \%$ with BAK (Alcon Inc) ${ }^{a}$ & $62.14 \pm 3.71$ \\
\hline BT $0.2 \%$ with BAK (Allergan Inc) ${ }^{a}$ & $63.61 \pm 3.81$ \\
\hline BT $0.15 \%$ without BAK (Allergan Inc) & $40.36 \pm 3.17$ \\
\hline BAK-S $\mathbf{S}^{\mathrm{b}}$ & $41.02 \pm 2.17$ \\
\hline PBS $^{\mathrm{C}}$ & $37.57 \pm 2.14$ \\
\hline ZAS $^{d}$ & $77.21 \pm 3.95$ \\
\hline $\mathbf{f M L P}^{\mathrm{d}}$ & $100.71 \pm 3.94$ \\
\hline
\end{tabular}

(Mean migration \pm standard deviation in $\boldsymbol{\mu m}$ )

${ }^{a}$ Drugs inducing significant chemotaxis $(p<0.01$ versus PBS controls)

${ }^{b}$ Drugs inducing no significant chemotactic effect ( $p>0.05$ versus PBS controls)

CNegative control

${ }^{\mathrm{d} P o s i t i v e ~ c o n t r o l s}$

\section{Discussion}

The study of the inflammatory response often requires the isolation of leukocytes, a key cell type responsible for the recognition and elimination of harmful substances. Leukocytes are intimately involved in the process of acute inflammation. Various methods have been described to isolate circulating leukocytes, including density centrifugation, flow cytometry, and spontaneous sedimentation. Several methods employ density gradients, especially for the isolation of neutrophils, blood cells, and polymorphic nuclear leukocytes.

The presence of chemotactic compounds, as preservatives and/or excipients is a significant factor associated with the inflammatory potential of many commercial ophthalmic preparations. Avoiding these drugs or adjusting treatment intervals may help to eliminate or decrease the consequent iatrogenic inflammation. This factor is especially important in patients who already have chronic ocular inflammation due to other conditions. An alternative approach to minimize chemotactic activity is to reformulate the concentration of active compounds in topical ophthalmic preparations, thereby reducing inflammation, enhancing compliance and ultimately higher rates of therapeutic success.

Three previous studies have investigated the role of topical pharmaceutical agents on leukocyte migration 
Table 2 Comparison among alpha 2-adrenergic agonists effects on neutrophil migration

\begin{tabular}{llll}
\hline Drugs & $\begin{array}{l}\text { Mean } \\
\text { difference }\end{array}$ & $\begin{array}{l}\text { Standard } \\
\text { error }\end{array}$ & Significance \\
\hline $\begin{array}{l}\text { BT without BAK } \\
\text { versus BT with BAK } \\
\text { (Allergan Inc) }\end{array}$ & -23.25 & 1.26 & $P=0.00^{*}$ \\
$\begin{array}{l}\text { BT without BAK } \\
\text { versus BT with BAK }\end{array}$ & -21.78 & 1.26 & $P=0.00^{*}$ \\
$\begin{array}{l}\text { (Alcon Inc) } \\
\text { BT with BAK (Allergan Inc) } \\
\text { versus BT with BAK }\end{array}$ & & \\
$\begin{array}{l}\text { (Alcon Inc) } \\
\text { "Statistically significant difference, post hoc Least Significant Difference (LSD), } \\
p<0.01 \text { was considered significant }\end{array}$ & 1.26 & $P=0.25$ \\
\end{tabular}

[26, 31, 32]. However, only one examined multiple antiglaucomatous drugs, including beta blockers, cholinergic agonists and nonselective adrenergic agonists [26]. To the best of our knowledge, our study is the first to examine the role of different alpha-2 selective adrenergic agonist (brimonidine) concentrations on neutrophil migration. Previously, BT has been associated with the development of anterior uveitis in patients, supporting our data that suggest that the drug has strong chemoattractant properties when compared to other formulations [33-35].

The cytotoxic effects of excipients used in ophthalmic formulations on human corneal epithelial cells have previously been related to prostaglandin analogs. In vivo and in vitro studies have shown that BAK induces both concentration-dependent and time-dependent cytotoxicity to the human corneal epithelium. Macrophage infiltration in the eyelids and visible defects in conjunctival cells were also described. Various ocular side effects of prostaglandin have been described in the literature, including foreign body sensation, ocular pruritus, a decrease in vision, reactivation of uveitis, herpes infection of the cornea, bacterial keratitis, and swelling of the retina (macular edema). Additionally, glaucoma patients treated with topical prostaglandin analogs have a higher incidence of dry eye syndrome and meibomian gland dysfunction. Yet, we could not find any published study on the leukocyte activity associated with prostaglandin analogs, one of the most frequently prescribed drugs for glaucoma treatment and a known proinflammatory molecule. We reiterate that the chemotactic properties of BAK, prostaglandins and other active and nonactive ingredients of hypotensive eye drops should continue to be the subject of future laboratory studies [36-38].

In our study, BT $0.15 \%$ with $0.005 \%$ SOC had no measurable chemotactic activity compared to the negative controls, such as BAK $0.005 \%$ solution. Our data suggests that BT formulations have a dose-dependent activation of the mediators of inflammation [13-15, 17, 23]. Therefore, the toxicity of a topical medication could be avoided by keeping the concentration of the active drug, BT in our case, under a certain threshold (Tables 1 and 2).

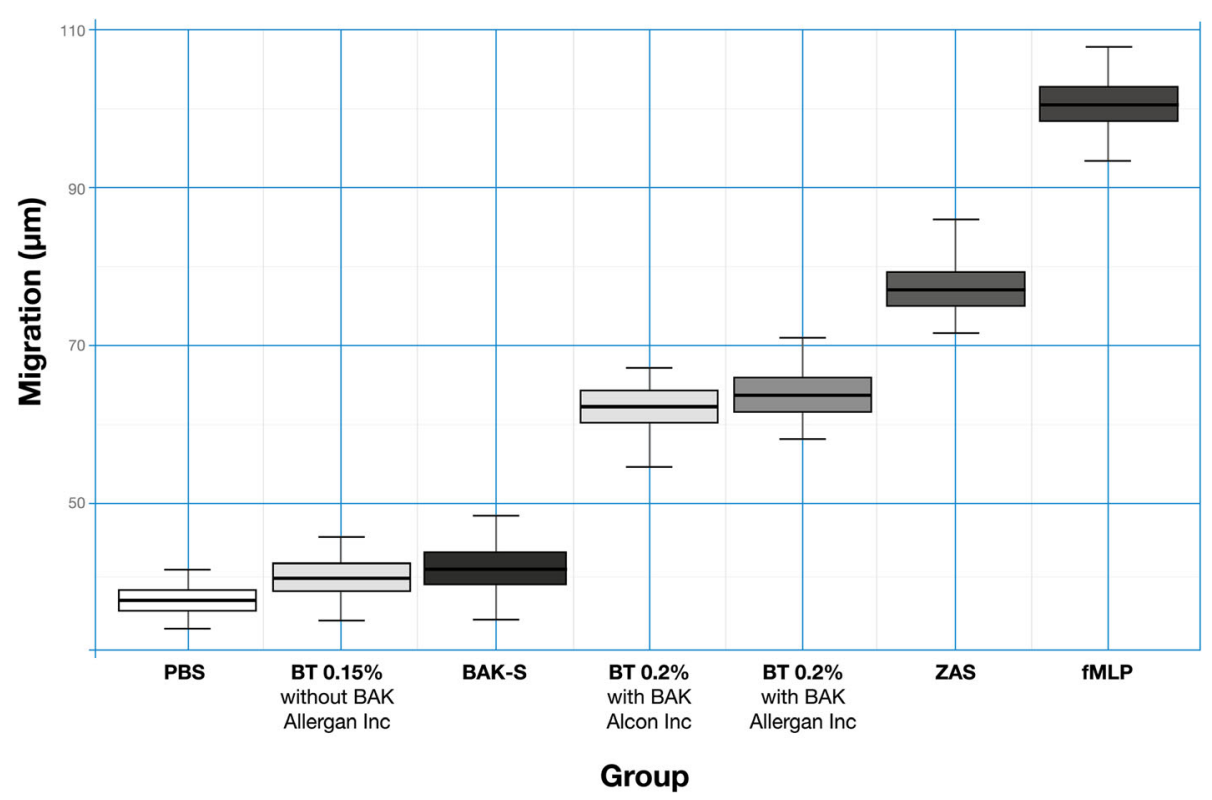

Fig. 2 X-axis: Migration through the matrix measured in micrometers ( $\mu \mathrm{m})$; Y-axis: each experimental condition, including controls. BT 0.15\% without BAK and BAK 0.005\% alone had no significant chemotactic effect, while BT 0.2\% with BAK 0.005\% (Alcon Laboratories Inc.) and BT 0.2\% with BAK $0.005 \%$ (Allergan Inc.) showed significantly higher chemotactic activity. Both the positive controls, ZAS and fMLP, showed the highest chemotactic effect, demonstrated by the longest migration distances of neutrophils through the matrix, as expected. Cells in the PBS negative control showed a negligible migration 
Several commonly used ophthalmic agents include BAK as a preservative and have been shown to increase neutrophil migration [26,33]. Those include mydriatics, corticosteroids, nonsteroidal anti-inflammatory agents, antiallergy medications, antiglaucomatous agents, and some artificial tears. As these drugs are often used on a chronic basis, this inflammatory effect is clinically relevant, especially in patients with glaucoma or ocular surface disease (OSD). This has led to the development of less toxic preservatives to replace BAK, including detergents such as polyquaternium-1 (Polyquad'; Alcon Laboratories Inc.). In addition, newer classes of preservatives have been developed, such as stabilized oxidizing agents (stabilized oxychloro complexes [SOCs]) and ionic-buffered preservatives (SofZia ${ }^{\circ}$; Alcon Laboratories Inc.) $[35,39]$.

It is important of consider BAK when choosing the ideal eye drop for a patient with glaucoma, because those patients often use eyedrops that also contain BAK for different ocular conditions, such as Ocular surface disease (OSD). OSD is a common comorbidity in glaucoma patients, and its prevalence increases with age [40-42]. Artificial tears and antiglaucoma medications are frequently used for prolonged periods of time, sometimes even for an entire lifetime. Several authors have demonstrated that BAK can induce tear film instability, ocular surface damage, a decrease in the number of goblet cells, an increase in macrophage and fibroblast counts in the conjunctiva, and an increase in the expression of inflammatory markers on the conjunctiva [43]. These effects can lead to ocular discomfort, poor intraocular pressure control, glaucoma surgery failure, and decreased patient compliance [44].

Subclinical inflammation present in conjunctival and subconjunctival space caused by fibroblast activation and inflammatory cell infiltration has also been largely described in studies with patients receiving antiglaucoma therapy for long periods of time. Our findings support the idea that reduced-dose BT without BAK is a better option than BT with BAK for patients with glaucoma and ocular hypertension and could minimize the risk of inflammation. Choosing a formulation less prone to inflammation is also important when the drug is prescribed postoperatively, as some patients require complementary topical therapy after glaucoma surgery to achieve the target pressure and reduce symptoms. An increased inflammatory response during the healing phase and subsequent subconjunctival fibrosis may block aqueous outflow and lead to surgical failure [43, 45]. There is indeed an increasing amount of evidence from clinical and experimental studies that the long-term use of topical drugs can increase the potential risk of treatment failure after further glaucoma surgery due to chronic ocular surface changes.

\section{Conclusion}

In summary, several studies have demonstrated that the use of ocular medications can cause significant iatrogenic effects on the eye. Therefore, when recommending an ocular hypotensive drug, the leukocyte chemotactic activities induced by antiglaucomatous formulations should also be considered, in order to reduce associated inflammation. In our study, we demonstrated that a formulation with a lower dose of BT without BAK showed no significant chemotactic effects, while the BT formulations with BAK showed statistically higher leukocyte chemotactic activity. Choosing the former should minimize iatrogenic inflammatory processes in patients with glaucoma or ocular hypertension, decreasing sideeffects, increasing compliance and treatment success.

\section{Abbreviations}

BT: Brimonidine tartrate; BAK: Benzalkonium chloride; IOP: Intraocular pressure; SOC: Stabilized oxychloride complex; FCS: Fetal calf serum; BAKS: Benzalkonium chloride solution; ZAS: Zymosan activated serum; fMLP: Formyl-methionine-leucine-phenylalanine peptides; PBS: Phosphate buffered saline; $\mu \mathrm{m}$ : Micrometers; LSD: Least significant difference; OSD: Ocular surface disease

\section{Acknowledgements}

Not applicable.

\section{Disclosure}

The authors have no proprietary or commercial interest in any materials discussed in this article.

\section{Authors' contributions}

RSA and MPV were major's contributors in the study design, data analysis, result interpretation, and performed the histological examination. MNB, HPS and EFD contributed to design, analysis, and interpretation of data and revising the manuscript critically for important intellectual content. All authors read and approved the final manuscript.

\section{Funding}

This research was self-funded.

\section{Availability of data and materials \\ The datasets used and/or analyzed during the current study available from the corresponding author on reasonable request.}

\section{Ethics approval and consent to participate}

Written authorization in the consent form was obtained to collect a blood sample from healthy volunteers. The entire procedure was authorized by the university's research ethics committee (CEP) and by the national research commission (CONEP) under registration number 1.466.576.

Consent for publication

Not Applicable.

\section{Competing interests}

The authors declare that they have no competing interests.

\section{Author details}

${ }^{1}$ Department of Ophthalmology, Fluminense Federal University, Niteroi, Rio de Janeiro, Brazil. ${ }^{2}$ The Henry C. Witelson Ocular Pathology Laboratory, McGill University, Montreal, Canada. 
Received: 9 September 2019 Accepted: 4 March 2020

Published online: 23 March 2020

\section{References}

1. Melamed S, David R. Ongoing clinical assessment of the safety profile and efficacy of brimonidine compared with timolol: year-three results. Brimonidine Study Group II. Clin Ther. 2000;22(1):103-11.

2. Walters TR. Development and use of brimonidine in treating acute and chronic elevations of intraocular pressure: a review of safety, efficacy, dose response, and dosing studies. Surv Ophthalmol. 1996;41:19-26.

3. Toris CB, Gleaseon ML, Camras CB, Yablonski ME. Effects brimonidine on aqueous humor dynamics in human eyes. Arch Ophthalmol. 1995;113:1513-7.

4. Schuman JS, Horwitz B, Choplin NT, David R, Albracht D, Chen K. A 1-year study of brimonidine twice-daily in glaucoma and ocular hypertension: a controlled, randomized, multicenter clinical trial. The Chronic Brimonidine Study Group. Arch Ophthalmol. 1997;115:847-52.

5. Lee DA. Efficacy of brimonidine as replacement therapy in patients with open-angle glaucoma or ocular hypertension. Clin Ther. 2000;22:53-65.

6. Lee DA, Gornbein J, Abrams C. The effectiveness and safety of brimonidine as mono, combination, or replacement therapy for patients with primary open-angle glaucoma or ocular hypertension: a post hoc analysis of an open-label community trial. The Glaucoma Trial Study Group. J Ocu Pharmacol Ther. 2000;16:3-18.

7. Schuman JS. Clinical experience with brimonidine $0.2 \%$ and timolol $0.5 \%$ in glaucoma and ocular hypertension. Surv Ophthalmol. 1996;41:27-S37.

8. Serle JB. A comparison of the safety and efficacy of twice-daily brimonidine $0.2 \%$ versus betaxolol $0.25 \%$ in subjects with elevated intraocular pressure. The Brimonidine Study Group. Surv Ophthalmol. 1996;41:39-\$47.

9. Katz LJ. Brimonidine tartrate $0.2 \%$ twice-daily vs. timolol $0.5 \%$ twice-daily: $1-$ year results in glaucoma patients. Brimonidine Study Group. Am J Ophthalmol. 1999;127:20-6.

10. LeBlanc RP. Twelve-month results of an ongoing randomized trial comparing brimonidine tartrate $0.2 \%$ and timolol $0.5 \%$ given twice daily in glaucoma or ocular hypertension. The Brimonidine Study Group. Ophthalmology. 1998;105:1960-7.

11. Javitt J, Goldberg I. Comparison of the clinical success rates and quality of life effects of brimonidine tartrate $0.2 \%$ and betaxolol $0.25 \%$ suspension in patients with open-angle glaucoma and ocular hypertension. Brimonidine Outcomes Study Group II. J Glaucoma. 2000;9:398-408.

12. Berdy GJ, Abelson MB, Smith LM, George MA. Preservative-free artificial preparations. Assessment of corneal epithelial toxic effects. Arch Ophthalmol. 1992;110:528-32.

13. Pisella PJ, Fillacier K, Elena PP, Debbasch C, Baudouin C. Comparison of the effects of preserved and unpreserved formulations of timolol on the ocular surface of albino rabbits. Ophthalmic Res. 1992;32:3-8.

14. Gasset AR, Ishii Y, Kaufman HE, Miller T. Cytotoxicity of ophthalmic preservatives. Am J Ophthalmol. 1974;78:98-105.

15. De Saint JM, Debbasch C, Brignole F, Rat P, Warnet JM, Baoudouin C. Toxicity of preserved and unpreserved glaucoma topical drugs in an in vivo model of conjunctival cells. Curr Eye Res. 2000;20:85-94.

16. Grant R, Ajello M, Vlass E. Salt water or high tech? A look at two new rising solutions for contact lenses. Optician. 1996;212:38-41.

17. Tu E. Balancing antimicrobial efficacy and toxicity of currently available topical ophthalmic preservatives. Saudi J Ophthalmol. 2014;28:182-7.

18. Data on file. Department of Pharmacokinetics and Drug Metabolism. Irvine: Allergan; 1999

19. Katz $L$. Twelve-month evaluation of brimonidine-purite versus brimonidine in patients with glaucoma or ocular hypertension. J Glaucoma. 2002;11:119-26.

20. Mundorf T, Williams R, Whitcup S, Felix C, Batoosingh A. A 3-month comparison of efficacy ans safety of brimonidine-purite $0.15 \%$ and brimonidine $0.2 \%$ in patients with glaucoma or ocular hypertension. J Ocul Pharmacol Ther. 2003;19:37-44.

21. Abud TB, Escuoteguazza Filho M, Oliveira ESS, Abud JF, Prata JA Jr. Hypotensive effect of three different formulations of brimonidine tartrate in normal eyes. Arq Bras Oftalmol. 2013;76:69-71.

22. Kim $\mathrm{CY}$, Hong $\mathrm{S}$, Seong GJ. Brimonidine $0.2 \%$ versus brimonidine Purite 0 . 15\% in Asian ocular hypertension. J Ocul Pharmacol Ther. 2007;23:481-6.

23. Noecker RJ, Herrygers LA, Anwaruddin R. Corneal and conjunctival changes caused by commonly used glaucoma medications. Cornea. 2004;23:490-6.

24. Patten JT, Cavanagh HD, Allansmith MR. Induced ocular pseudopenphigoid. Am J Ophthalmol. 1976;82:272-6.
25. Van Buskirk EM. Adverse reactions from timolol administration. Ophthalmology. 1980:87:447-50.

26. Ozdal PC, Deschenês J, Rudzinski M, Antecka E, Baines MG. Chemotactic and chemokinetic properties of topical ophthalmic preparations. Curr Eye Res. 2002:25:363-8

27. Rosenbaum JT, Raymond WW, Fujikawa LS, Langois L, Palestine AG, Stamper $\mathrm{RL}$, et al. Chemotactic activity in aqueous humor from patients with anterior uveitis. Clin Immunol Immunopathol. 1987;42:265-73.

28. The International Council of Ophthalmology (ICO). Guidelines for glaucoma eye care. 2015. Available at: http://www.icoph.org/ICOGlaucomaGuidelines.pdf.

29. Heijl A, Leske MC, Hyman $L$, et al. Intraocular pressure reduction with a fixed treatment protocol in the early manifest glaucoma trial. Acta Ophthalmol. 2011:89(8):749-54

30. American Academy of Ophthalmology Glaucoma Primary Open Angle Glaucoma Committee. Preferred practice pattern ${ }^{\circledast}$ guidelines. San Francisco: American Academy of Ophthalmology; 2015. Available at: www.aao.org/ppp.

31. Tsai E, Till GO, Marak GE. Effects of mydriatic agents on neutrophil migration. Ophthalmic Res. 1988;20:14-9.

32. Beltz J, Zamir E. Brimonidine induced anterior uveitis. Ocul Immunol Inflamm. 2016:24(2):128-33.

33. Byles DB, Frith P, Salmon JF. Anterior uveitis as a side effect of topical brimonidine. Am J Ophthalmol. 2000:130:287-91.

34. Goyal R, Ram AR. Brimonidine tartrate 0.2\% (Alphagan) associated granulomatous anterior uveitis. Eye. 2000;14:908-10.

35. Becker HI, Walton RC, Diamant Jl, Zegans ME. Anterior uveitis and concurrent allergic conjunctivitis associated with long-term use of topical 0 . 2\% brimonidine tartrate. Arch Ophthalmol. 2004;122:1063-6.

36. Alm A. Latanoprost in the treatment of glaucoma. Clin Ophthalmol. 2014;8: 1967-85.

37. Hakkarainen JJ, Reinisalo M, Ragauskas S, Seppanen A, Kaja S, Kalesnylas G. Acute cytotoxic effects of marketed ophthalmic formulations on human corneal epithelial cells. Int J Pharm. 2016;511:73-8.

38. Trezeciecka A, Paterno JJ, Toropainen E, Koskela A, Podracka L, Korhonen E, et al. Long-term topical application of preservative prostaglandin analogues evokes macrophage infiltration in the ocular adnexa. Eur J Pharmacol. 2016; 788:12-20.

39. Freeman PD, Kahook MY. Preservatives in topical ophthalmic medications: historical and clinical perspectives. Expert Rev Ophthalmol. 2009;4:59-64

40. Friedman DS, Wolfs RC, O'Colmain BJ, Klein BE, Taylor HR, West S, et al. Eye Diseases Prevalence Research Group. Prevalence of open-angle glaucoma among adults in the United States. Arch Ophthalmol. 2004;122:532-8.

41. Schaumberg DA, Sullivan DA, Buring JE, Dana MR. Prevalence of dry eye syndrome among US women. Am J Ophthalmol. 2003;136:318-26.

42. Schaumberg DA, Dana R, Buring JE, Sullivan DA. Prevalence of dry eye disease among US men: estimates from the Physician's Health Studies. Arch Ophthalmol. 2009:127:763-8

43. Baudouin C, Labbè A, Liang H, Pauly A, Brignole-Baudouin F. Preservatives in eye drops: the good, the bad and the ugly. Prog Retin Eye Res. 2010;29: 312-34

44. Baudoin C. Ocular surface and external filtration surgery: mutual relationships. Dev Ophthalmol. 2012;50:64-78.

45. Baudoin C. Ocular surface and external filtration surgery: mutual relationships. Dev Ophthalmol. 2017:59:67-79.

\section{Publisher's Note}

Springer Nature remains neutral with regard to jurisdictional claims in published maps and institutional affiliations.

Ready to submit your research? Choose BMC and benefit from:

- fast, convenient online submission

- thorough peer review by experienced researchers in your field

- rapid publication on acceptance

- support for research data, including large and complex data types

- gold Open Access which fosters wider collaboration and increased citations

- maximum visibility for your research: over $100 \mathrm{M}$ website views per year

At BMC, research is always in progress.

Learn more biomedcentral.com/submission 